\title{
ІНФОРМАТИВНЕ ЗНАЧЕННЯ ВІЗУАЛЬНОГО АНАЛІЗУ АРТЕРІАЛЬНОЇ ОСЦИЛОГРАМИ, ЗАРЕЄСТРОВАНОЇ ПІД ЧАС ЗРОСТАННЯ КОМПРЕСІЇ ПЛЕЧА ПРИ ВИМІРЮВАННІ АРТЕРІАЛЬНОГО ТИСКУ
}

\author{
В. П. Марценюк, Д. В. Вакуленко ${ }^{1}$, Л. О. Вакуленкоㄹ, \\ О. В. Кутакова ${ }^{3}$ А. В. Семенець ${ }^{1}$, \\ Н. О. Кравець ${ }^{1}$, Н. Я. Климук ${ }^{1}$ \\ Університет Бєльсько-Бяли, Республіка Польща \\ ${ }^{1}$ ДВНЗ «Тернопільський державний медичний університет \\ імені І. Я. Горбачевського МОЗ України» \\ ${ }^{2}$ Тернопільський національний педагогічний університет імені Володимира Гнатюка \\ ${ }^{3}$ Національна медична академія післядипломної освіти імені П. Л. Шупика

\begin{abstract}
Відомо, що захворювання серцево-судинної системи відносяться до найбільш поширених захворювань людства. Особливо насторожує «помолодшання» судинних катастроф, що призводять до глибокої інвалідності. Значною мірою благополуччя кровообігу залежить від стану судин - „периферійного серця”. Одним із методів його оцінювання $€$ артеріальна осцилографрія (АО). Представлені дослідження базуються на аналізі 1640 АО, зареєстрованих за допомогою електронного тонометра ВАТ 41-2 під час вимірювання АТ. Для морфологічного аналізу АО пропонується використовувати такі критерії: а) фрорма всієї осцилограми; б) характер окремих пульсацій у різних фразах компресії. Дослідження дали можливість виявити різні види судинної реакції на компресію плеча під час вимірювання АТ у стані спокою (на лівому та правому плечі), після впливу різноманітних чинників і в процесі відновлення після них. Використання запропонованих авторами методів морфологічного аналізу АO, їх оцінка та клінічна інтерпретація значно підвищують іноормативність процесу вимірювання АT.
\end{abstract}

Ключові слова: артеріальна осцилографрія, судини, якість адаптації.

\section{INFORMATIONAL VALUE OF VISUAL ANALYSIS OF ARTERIAL OSCILLOGRAPHY, DETERMINED AT THE TIME OF GROWTH OF FOOT COMPRESSION AFTER MEASUREMENT OF ARTERIAL PRESSURE}

\author{
V. P. Martsenyuk, D. V. Vakulenkoㅁ, L. A. Vakulenko², \\ A. V. Kutakova ${ }^{3}$, A. V. Semenets ${ }^{1}$, \\ N. A. Kravets ${ }^{1}$, N. J. Klimuk ${ }^{1}$ \\ University of Bielsko-Biala, the Republic of Poland \\ ${ }^{1}$ SHEE I. Horbachevsky Ternopil State Medical University of the Ministry of Health of Ukraine \\ ${ }^{2}$ Ternopil Volodymyr Hnatiuk National Pedagogical University \\ ${ }^{3}$ Shupyk National Medical Academy of Postgraduate Education
}

\begin{abstract}
Background. The implementation of modern ICT in health care practice makes it possible to improve prevention, diagnosis, early rehabilitation and treatment of cardiovascular system (CVS). According to the World Health Organization each year cardiovascular diseases (CVD) cause the death of 17.5 million persons; it is $31 \%$ of all deaths worldwide). High blood pressure is a major risk factor for heart attacks. The current instrumental diagnostics of CVS disorders by ultrasonic Doppler examination, ultrasound scanning and digital optical capillaroscopy, MR angiography, mathematical analysis of cardiac rhythm, Holter monitoring (and other methods) contribute to improving the diagnosis and treatment of CVS diseases. However, «rejuvenating» of vascular disorders that lead to profound disability, indicates that today there is an urgent need in fundamental studies on cardiovascular system, changes in cases of pathological conditions, effective technologies for early detection and treatment of vascular pathology.

Materials and methods. Arterial oscillogram obtained using monitor of blood pressure and heart rate, which records the value of pressure pulse changes in cuff when measuring blood pressure and export information through an external
\end{abstract}

(с) В. П. Марценюк, Д. В. Вакуленко, Л. О. Вакуленко, О. В. Кутакова, А. В. Семенець, Н. О. Кравець, Н. Я. Климук 
interface of data exchange to personal computer. Further analysis of the obtained data and creating of arterial oscillogram was conducted by computer programs developed by the authors.

The results of our research are based on assessment during 2012-2017. 626 people - volunteers were divided into 2 groups. The first group consisted of 480 healthy males $(27 \%)$ and females (73\%), aged 18 - 22 years, who study in the medical and pedagogical universities of Ternopil, Ukraine.

Results. The authors suggested morphological criteria of oscillograms evaluation, defined standards of normal findings; developed the ICT methods of value oscillogram evaluation, differentiated 5 levels of deviations from the norm, which are compared with 5 types of health level gradation established in electrocardiography.

Morphological oscillogram analysis enables visual evaluation of vessels condition before compression and their oscillatory ability to counteract compression increase by the cuff when measuring blood pressure. The nature of pulsation will help the doctor to examine pulsation rhythm, cardiac function, and condition of the autonomic nervous system, blood pressure and neuro-reflex effects on the blood vessels state, differentiate functional and organic causes of changes in them. The use of the suggested morphological criteria of value oscillogram evaluation to estimate health condition will help the doctor to take appropriate decisions both during primary examination, and for monitoring the effectiveness of treatment.

Conclusions. So, the suggested information technology enables medical professionals to expand information on cardiovascular system of patients, promote early revealing of premorbid and donozological state and help to plan diagnostics and therapy. They will be useful for general physicians, paediatricians, cardiologists, neurologists, researchers, in sports medicine. General physicians (or other users) in the presence of electronic sphygmomanometer and the software will be able to monitor CVS state and peripheral vessels according to the suggested criteria.

Key words: arterial oscillography, vessels, quality of adaptation.

\title{
ИНФОРМАТИВНОЕ ЗНАЧЕНИЕ ВИЗУАЛЬНОГО АНАЛИЗА АРТЕРИАЛЬНОЙ ОСЦИЛЛОГРАММЫ, ЗАРЕГИСТРИРОВАННОЙ ВО ВРЕМЯ РОСТА КОМПРЕССИИ ПЛЕЧА ПРИ ИЗМЕРЕНИИ АРТЕРИАЛЬНОГО ДАВЛЕНИЯ
}

\author{
В. П. Марценюк, Д. В. Вакуленко ${ }^{1}$ Л. А. Вакуленкоㄹ, \\ О. В. Кутакова ${ }^{3}$, А. В. Семенець ${ }^{1}$, \\ Н. А. Кравець ${ }^{1}$, Н. Я. Климук ${ }^{1}$ \\ Университет Бельско-Бялы, Республика Польша

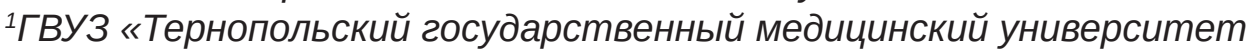 \\ имени И. Я. Горбачевского МЗ Украины» \\ ${ }^{2}$ Тернопольський национальный педагогический университет имени Владимира Гнатюка \\ зНациональная медицинская академия последипломного образования имени П. Л. Шупика

\begin{abstract}
Внедрение современных информационно-коммуникационных технологий (ИКТ) в практику здравоохранения по(ССC). Известно, что заболевания ССС относятся к наиболее распространенным заболеваниям человечества. В значительной степени благополучие кровообращения зависит от состояния сосудов - «периферийного сердца». Одним из методов его оценки является артериальная осциллография (АО). В работе представлены результаты исследований, базирующихся на анализе 1640 АО, зарегистрированных с помощью электронного тонометра ОАО всей осциллограммы; б) характер отдельных пульсаций в различных фразах компрессии.

Исследования позволили выявить различные виды сосудистой реакции на компрессию плеча во время измере-
\end{abstract} \\ зволяет улучшить профилактику, диагностику, раннюю реабилитацию и лечение сердечно-сосудистой системы \\ 41-2 при измерении АД. Для морфологического анализа АО предложено использовать такие критерии: а) фрорма \\ ния АД в состоянии покоя (на левом и правом плече), после воздействия различных факторов и в процессе восста- \\ новления после них. Использование предложенных авторами методов морфологического анализа АО, их оценка и \\ клиническая интерпретация значительно повышают информативность процесса измерения АД.
}

Ключевые слова: артериальная осциллография, сосуды, качество адаптации. 
Вступ. Захворювання серцево-судинної системи, за даними ВООЗ, відносяться до найбільш поширених захворювань людства. Особливо насторожує «помолодшання» судинних катастроф, які призводять до глибокої інвалідності [1]. Значною мірою благополуччя кровообігу залежить від стану судин — «периферійного серця» [3]. Одним із методів його оцінки $€$ артеріальна осцилографія. Застосування сучасного електронного обладнання може сприяти підвищенню інформативності указаного методу дослідження. Артеріальні форми сигналу, що реєструється під час вимірювання артеріального тиску (АТ), окрім значень систолічного, діастолічного, середнього АТ містять низку інформації, яка може дати більш глибоке уявлення про загальний стан гемодинаміки [3, 4].

Мета дослідження: вдосконалити інформативні можливості процесу та результатів вимірювання АТ. Розробити критерії для проведення морфологічного аналізу артеріальної осцилограми (АО), вивчити динаміку морфологічної картини АО залежно від ступеня компресії плеча манжетою. Розробити рекомендації щодо вивчення та оцінювання стану серцево-судинної системи шляхом аналізу АО за їхніми морфологічними характеристиками.

Матеріал і методи дослідження. Дослідження базуються на аналізі 1640 АО, зареєстрованих за допомого електронного тонометра ВАТ 41-2 під час вимірювання АТ у стані спокою та після впливу різноманітних (фізичних, термічних, психоемоційних та ін.) чинників [2]. У зв'язку з відсутністю подібних досліджень, для морфологічного аналізу АО авторами використано інформацію щодо механіки кровообігу [9], плетизмографії, реографії [5-7], АО [3, 4, 8]. Розроблено критерії їх оцінки та клінічної інтерпретації, оцінювання та прийняття рішень лікарем.

Для морфологічного аналізу АО пропонується використовувати такі критерії:

а) форма усієї осцилограми (характеристика огинаючих, ритмічність пульсацій, рівномірність зростання та зниження амплітуди осциляцій в процесі збільшення компресії), наявність та кількість максимальних осциляцій з однаковою амплітудою;

б) характер окремих пульсацій в різних фазах компресії (їхня амплітуда, кути екстремумів, висхідна та низхідна частини); наявність, локалізація, величина дикротичної та додаткових хвиль на окремих осциляціях.

Результати та їх обговорення. Для морфологічного оцінки АО використано розроблені авторами

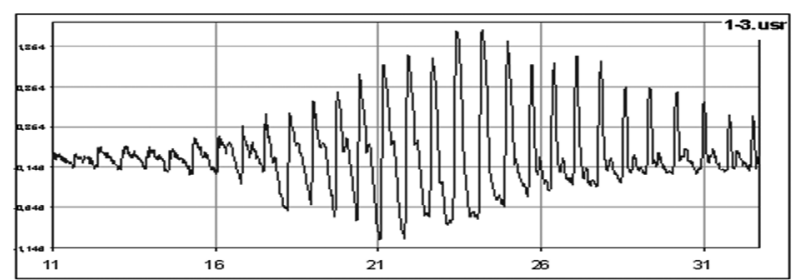

1-й тип

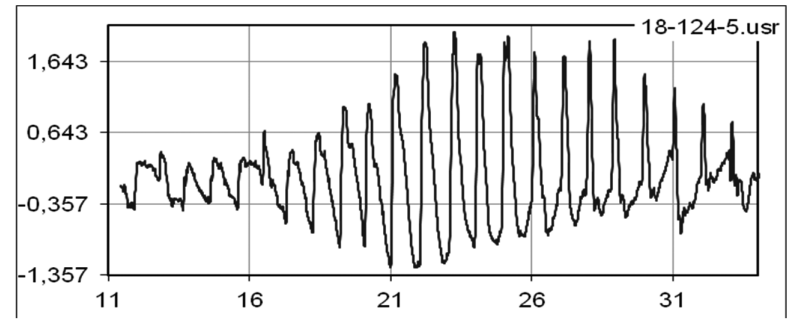

2-й тип

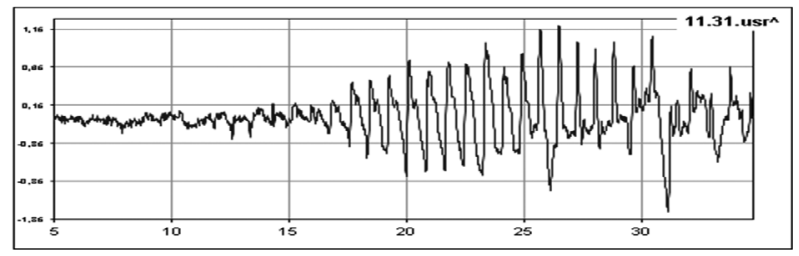

3-й тип

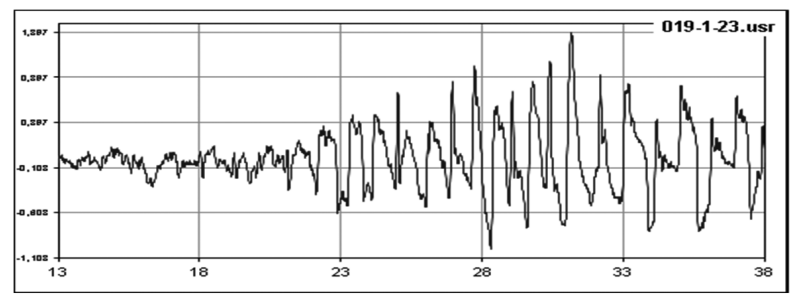

4-й тип

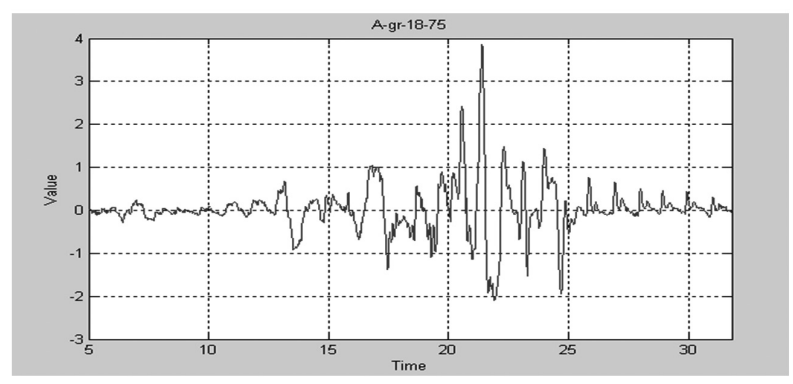

5-й тип

Рис. 1. Типи АО, диференційованих за ритмічністю пульсацій, їхньою формою та динамікою зростання та спадання амплітуд. По осі $\mathrm{X}$ - час реєстрації осцилограми (с), по осі Y — значення коливань тиску в манжеті під впливом пульсацій судинної стінки артерії 
інформаційні технології вагової оцінки як окремих пульсацій, так і усієї АО, диференційованої за 5 ступенями (типами) відповідності ознакам, прийнятим за норму [2] (рис. 1).

Дослідження дали можливість виявити різні види судинної реакції на компресію плеча під час вимірювання АТ у стані спокою (на лівому та правому плечі), після впливу різноманітних чинників та в процесі відновлення після них.

Виявлено відхилення від прийнятої нами норми у 35\% осіб молодого віку у стані спокою, зниження адаптаційних можливостей організму за показниками функціональних проб, навіть найпростішої з них - ортостатичної проби, що відповідає даним інших авторів [1]. Отримані результати аналізу та оцінки типу АО співставлено з 5 варіантами градації рівня здоров’я, створеними за фізіологічною інтерпретацією варіабельності серцевого

\section{Література.}

1. Баевский Р. М. Оценка адаптационных возможностей организма и риск развития заболеваний / Р. М. Баевский, А. П. Берсенева. - М. : Медицина, 1997. -265 c.

2. Вакуленко Д. В. Інформаційна система морфологічного, часового, частотного та кореляційного аналізу артеріальних осцилограм у фізичній реабілітації : монографія / Д. В. Вакуленко. - Тернопіль : ТДМУ, 2015. - 212 с.

3. Покровский А. В. Клиническая ангіологія / А. В. Покровський. - М. : Медицина, 1979. - 366 с.

4. Esper S. A. Arterial waveform analysis / S. A. Esper, M. R. Pinsky // Best Pract. Res. Clin. Anaesthesiol. 2014ю - Vol. 28, No. 4. - P. 363-380.

5. Moxham I. M. Understanding arterial pressure waveforms: registrar prize / I. M. Moxham // Southern African Journal of Anaesthesia \& Analgesia. - 2003. - Vol. 9, No. 1. - P. 40-42.

6. Nirmalan M. Broader applications of arterial pressure wave form analysis /M. Nirmalan, M. D. Paul // Continuing Education in Anaesthesia, Critical Care \& Pain. - 2014. - Vol. 14, No. 6. - P. 285-290.

7. Noninvasively determined radial $\mathrm{dp} / \mathrm{dt}$ is a predictor of mortality in patients with heart failure / J. M. Tartière, J. Y. Tabet, D. Logeart [et al.] // Am. Heart J. — 2008. — Vol. 155, No. 4. — P. 758-763.

8. Romano S. M. Assessment of cardiac output from systemic arterial pressure in humans / S. M. Romano, M. Pistolesi // Crit. Care Med. - 2002. — Vol. 30, No. 8. - P. 1834-1841.

9. The mechanics of the circulation / C. G. Caro, T. J. Pedley, R. C. Schroter, W. A. Seed. - Cambridge : Cambridge University Press, 2012. — 2nd ed. — 528 p. ритму електрокардіосигналу за Р. М. Баєвським [1]. Співставлення дало можливість прийти до висновку, що особам з 3-м типом АО (умовно здоровий) необхідна корекція способу життя, з 4-м (стан передхвороби) — превентивна реабілітація, 3 5-м (хворий) - негайне обстеження і лікування.

\section{Висновки.}

Використання запропонованих авторами інформаційних технологій морфологічного аналізу АО, їх оцінка та клінічна інтерпретація значно підвищують інформативність процесу вимірювання АТ; можуть бути використані для раннього виявлення донозологічних і преморбідних станів та функціональних резервів системи кровообігу, що допоможе лікарю більш ефективно спланувати профілактичний, діагностичний та терапевтичний процес.

\section{References.}

1. Baevskij, R. M., Berseneva, A. P. (1997). Ocenka adaptacionnyh vozmozhnostej organizma i risk razvitija zabolevanij [Evaluation of the adaptive capacity of the body and the risk of disease]. Moscow: Medicina (Medicine).

2. Vakulenko, D. V. (2015). Informacijna sistema morfologichnogo, chasovogo, chastotnogo ta koreljacijnogo analizu arterial'nih oscilogram u fizichnij reabilitacii [Information system of morphological, time, frequency and correlation analysis of arterial waveforms in physical rehabilitation]. Ternopil': TSMU.

3. Pokrovskij, A. V. (1979). Klinicheskaja angiologija [Clinical angiology]. Moscow: Medicina (Medicine).

4. Esper, S. A., Pinsky, M. R. (2014). Arterial waveform analysis. Best Pract. Res. Clin. Anaesthesiol., 28(4), 363-380. doi: 10.1016/j.bpa.2014.08.002.

5. Moxham, I. M. (2003). Understanding arterial pressure waveforms: registrar prize. Southern African Journal of Anaesthesia \& Analgesia, 9(1), 40-42.

6. Nirmalan, M., Paul, M. D. (2014). Broader applications of arterial pressure wave form analysis. Continuing Education in Anaesthesia, Critical Care \& Pain, 14(6), 285-290. doi: 10.1093/bjaceaccp/mkt078.

7. Tartière, J. M., Tabet, J. Y., Logeart, D., Tartière-Kesri, L., Beauvais, F., Chavelas, C., \& Cohen Solal, A. (2008). Noninvasively determined radial $\mathrm{dp} / \mathrm{dt}$ is a predictor of mortality in patients with heart failure. Am. Heart J., 155(4), 758-763. doi: 10.1016/j.ahj.2007.11.030.

8. Romano, S. M., \& Pistolesi, M. (2002). Assessment of cardiac output from systemic arterial pressure in humans. Crit. Care Med., 30(8), 1834-1841.

9. Caro, C. G., Pedley, T. J., Schroter, R. C., \& Seed, W. A. (2012). The mechanics of the circulation. 2nd ed. Cambridge: Cambridge University Press. 